\section{Low complexity ZF receiver for orthogonal SFBC-OFDM in broadband wireless channels}

\author{
B. Özbek and D. Le Ruyet
}

\begin{abstract}
Orthogonal space-frequency block coded (SFBC) orthogona frequency division multiplexing (OFDM) systems are analysed in broadband wireless channels where adjacent subcarriers do not have the same channel coefficients and the matched filter receiver causes an error floor in bit error rate performance. To avoid this, a low complexity zero forcing (ZF) receiver for the orthogonal schemes with two and three transmit and one receive antennas are proposed
\end{abstract}

Introduction: Orthogonal frequency division multiplexing (OFDM) is the most promising technique to provide high data rates over broadband wireless channels. Multiple-input multiple-output (MIMO) systems can increase achievable capacity and mitigate fading effects through spatial diversity techniques. Hence, the combination of MIMO signal processing with OFDM can be applied as space-time block coded (STBC)-OFDM [1] or space-frequency block coded (SFBC)-OFDM [2]. In both cases, it is generally assumed that the channel coefficients are constant over neighbouring subcarriers or OFDM symbols in the orthogonal code.

In [3], the authors compared these two techniques. They showed that STBC-OFDM is superior to SFBC-OFDM for wireless channels with high delay spread. Indeed, the channel coefficients might not be constant over neighbouring subcarriers for SFBC-OFDM over severe frequency selective channels which have high delay spreads compared to the symbol duration. Therefore, the orthogonality of the code structure is no longer preserved. This causes an error floor in bit error rate (BER) performance owing to the interference that comes from the neighbouring symbols. However, SFBC-OFDM has an important advantage compared to STBC-OFDM, this being absence of decoding delay. To extend the application of SFBC-OFDM systems to broadband wireless channels, we propose a low complexity zero forcing (ZF) receiver which prevents this error floor using channel compensation for the orthogonal SFBC-OFDM with two and three transmit and one receive antennas.

Orthogonal SFBC-OFDM in broadband wireless channels: We consider an SFBC-OFDM system with $\mathrm{K}$ subcarriers, $\mathrm{N}_{\mathrm{t}}$ transmit and one receive antennas. For each OFDM symbol $\mathrm{n}$, the serial data symbols are converted into a data vector $\mathbf{S}_{\mathrm{n}}$ with duration $\mathrm{KT}_{\mathrm{s}}$ by a serial-to-parallel converter where $T_{\mathrm{s}}$ is the symbol duration. This vector is then space-frequency encoded and split into $\mathrm{N}_{t}$ vectors $\mathbf{C}_{n, \mathrm{i}}$. The orthogonal SFBC matrix consists of $\mathrm{Q}$ symbols over $\mathrm{T}_{\mathrm{f}}$ subcarriers providing the transmission rate $\mathrm{R}=\mathrm{Q} / \mathrm{T}_{\mathrm{f}}$. Each $\mathbf{C}_{\mathrm{n}, \mathrm{i}}$ is modulated by inverse fast Fourier transform (IFFT) into an OFDM symbol and the guard interval (GI) is added. The resulting vector is transmitted through the frequency selective fading channel that has $\mathrm{L}_{\mathrm{f}}$ channel taps. To avoid intersymbol interference, the length of GI is chosen as equal to or higher than the number of channel taps.

At the receiver, after removing the GI and applying FFT, the received signal is written in the matrix/vector form as

$$
\mathbf{R}_{\mathrm{n}}=\sum_{\mathrm{i}=1}^{\mathrm{N}_{\mathrm{t}}} \mathbf{C}_{\mathrm{n}, \mathrm{i}} \mathbf{H}_{\mathrm{n}, \mathrm{i}}+\mathbf{N}_{\mathrm{n}}
$$

where $\mathbf{R}_{\mathrm{n}}$ is the received vector, $\mathbf{H}_{\mathrm{n}, \mathrm{i}}$ is a diagonal channel matrix the elements of which are FFT of $h_{n, i}$ and $\mathbf{N}_{n}$ is the noise vector the elements of which are FFT of additive white Gaussian noise with zero mean and $\sigma_{\mathrm{n}}^{2}$ variance per real dimension. Throughout this Letter, we skip the OFDM symbol index $\mathrm{n}$ for simplicity in the representation.

Orthogonal SFBC-OFDM with two transmit antennas: We use the Alamouti STBC [4] through two adjacent subcarriers using two symbols. The data vector $\mathbf{S}$ is encoded into two vectors $\mathbf{C}_{1}$ and $\mathbf{C}_{2}$ that are transmitted from the first and second antenna simultaneously. Taking $\mathbf{C}_{1}$ and $\mathbf{C}_{2}$ into (1) and organising the received vector into blocks, we obtain

$$
\mathbf{R}_{\mathrm{k}^{\prime}}=\mathbf{H}_{\mathrm{k}^{\prime}} \mathbf{S}_{\mathrm{k}^{\prime}}+\mathbf{N}_{\mathrm{k}^{\prime}}
$$

where the subcarrier block index is $\mathrm{k}^{\prime}=1,2, \ldots, \mathrm{K} / \mathrm{T}_{\mathrm{f}}$, the transmitted vector is $\mathbf{S}_{\mathrm{k}^{\prime}}=\left[\mathrm{S}_{\mathrm{k}}, \mathrm{S}_{\mathrm{k}+1}\right]^{\mathrm{T}}$ and the channel transfer matrix

$$
\mathbf{H}_{\mathrm{k}^{\prime}}=\left[\begin{array}{cc}
\mathrm{H}_{1, \mathrm{k}} & \mathrm{H}_{2, \mathrm{k}} \\
\mathrm{H}_{2, \mathrm{k}+1}^{*} & -\mathrm{H}_{1, \mathrm{k}+1}^{*}
\end{array}\right]
$$

Note that the channel coefficients belonging to adjacent subcarriers are not equal for each antenna. The matched filter (MF) receiver can be applied to (2) to obtain the reconstructed symbols as

$$
\tilde{\mathbf{S}}_{\mathrm{k}^{\prime}}=\mathbf{H}_{\mathrm{k}^{\prime}}^{\mathrm{mf}} \mathbf{R}_{\mathrm{k}^{\prime}}
$$

where $\mathbf{H}_{\mathrm{k}^{\prime}}^{\mathrm{mf}}$ is the transpose-conjugate of the $\mathbf{H}_{\mathrm{k}^{\prime}}$. The symbols are then detected separately as

$$
\left[\begin{array}{c}
\tilde{S}_{k} \\
\tilde{S}_{k+1}
\end{array}\right]=\left[\begin{array}{cc}
D_{k} & \varepsilon_{k} \\
\varepsilon_{k}^{*} & D_{k+1}
\end{array}\right]\left[\begin{array}{c}
S_{k} \\
S_{k+1}
\end{array}\right]+\overline{\mathbf{N}}_{k^{\prime}}
$$

where $D_{k}=\left|H_{1, k}\right|^{2}+\left|H_{2, k+1}\right|^{2}$ and $D_{k+1}=\left|H_{2, k}\right|^{2}+\left|H_{1, k+1}\right|^{2}$ are the diversity gains and $\varepsilon_{\mathrm{k}}=\mathrm{H}_{2, \mathrm{k}} \mathrm{H}_{1, \mathrm{k}}^{*}-\mathrm{H}_{2, \mathrm{k}+1} \mathrm{H}_{1, \mathrm{k}+1}^{*}$ is the interference term. Using diversity gains, the normalised MF receiver is obtained as $\mathbf{H}_{\mathrm{k}^{\prime}}^{\mathrm{nmf}}=\operatorname{diag}\left(1 / \mathrm{D}_{\mathrm{k}}, 1 / \mathrm{D}_{\mathrm{k}+1}\right) \mathbf{H}_{\mathrm{k}^{\prime}}^{\mathrm{mf}}$.

The MF receiver achieves maximum diversity, however the symbol carried by the adjacent subcarrier causes interference which adds up to the noise. To avoid this error floor, we can use a ZF receiver which implies a $2 \times 2$ matrix inversion.

Orthogonal SFBC-OFDM with three transmit antennas: We apply the orthogonal STBC in [5] through four adjacent subcarriers using the three symbols at each OFDM symbol. Since the rate of the code is $3 / 4$, we map the $3 K / 4$ information symbols onto K subcarriers. After organising the OFDM symbol vector, it is encoded into three vectors $\mathbf{C}_{1}, \mathbf{C}_{2}, \mathbf{C}_{3}$, and then transmitted from three antennas simultaneously. The received signal is written as given in (2) where the channel transfer matrix for each block is

$$
\mathbf{H}_{\mathrm{k}^{\prime}}=\left[\begin{array}{ccc}
\mathrm{H}_{1, \mathrm{k}} & \mathrm{H}_{2, \mathrm{k}} & \mathrm{H}_{3, \mathrm{k}} \\
\mathrm{H}_{2, \mathrm{k}+1}^{*} & -\mathrm{H}_{1, \mathrm{k}+1}^{*} & 0 \\
-\mathrm{H}_{3, \mathrm{k}+2}^{*} & 0 & \mathrm{H}_{1, \mathrm{k}+2}^{*} \\
0 & -\mathrm{H}_{3, \mathrm{k}+3}^{*} & \mathrm{H}_{2, \mathrm{k}+3}^{*}
\end{array}\right]
$$

Similar to (3), using the MF receiver, we obtain

$$
\tilde{\mathbf{S}}_{\mathrm{k}^{\prime}}=\left[\begin{array}{ccc}
\mathrm{D}_{\mathrm{k}} & \varepsilon_{\mathrm{k}} & \varepsilon_{\mathrm{k}+1} \\
\varepsilon_{\mathrm{k}}^{*} & \mathrm{D}_{\mathrm{k}+1} & \varepsilon_{\mathrm{k}+2} \\
\varepsilon_{\mathrm{k}+1}^{*} & \varepsilon_{\mathrm{k}+2}^{*} & \mathrm{D}_{\mathrm{k}+2}
\end{array}\right] \mathbf{S}_{\mathrm{k}^{\prime}}+\overline{\mathbf{N}}_{\mathrm{k}^{\prime}}
$$

where $\mathrm{D}_{\mathrm{k}}, \mathrm{D}_{\mathrm{k}+1}$ and $\mathrm{D}_{\mathrm{k}+2}$ are the diversity gains and $\varepsilon_{\mathrm{k}}, \varepsilon_{\mathrm{k}+1}$ and $\varepsilon_{\mathrm{k}+2}$ are the interference terms defined as similar to orthogonal codes with two transmit antennas. The normalised MF receiver is then $\mathbf{H}_{\mathrm{k}^{\prime}}^{\mathrm{nmf}}=\operatorname{diag}\left(1 / \mathrm{D}_{\mathrm{k}}, 1 / \mathrm{D}_{\mathrm{k}+1}, 1 / \mathrm{D}_{\mathrm{k}+2}\right) \mathbf{H}_{\mathrm{k}^{\prime}}^{\mathrm{mf}}$. Similar to the Alamouti SFBC-OFDM, the $Z F$ receiver which implies a $4 \times 3$ matrix pseudo-inversion of (4) can be used.

Proposed low complexity $Z F$ receivers: To eliminate the interference terms caused by the MF receiver and provide diversity gains as in the classical ZF receiver, we propose to search for the $\mathbf{H}_{\mathbf{k}^{\prime}}^{\text {mzf }}$ matrix which satisfies $\mathbf{H}_{\mathrm{k}^{\prime}}^{\mathrm{mz} f} \mathbf{H}_{\mathrm{k}^{\prime}}=\operatorname{diag}\left(\overline{\mathrm{D}}_{\mathrm{k}}, \overline{\mathrm{D}}_{\mathrm{k}+1}\right)$. Using linear operations, for orthogonal SFBC-OFDM with $\mathrm{N}_{\mathrm{t}}=2$, the solution matrix is proposed as

$$
\mathbf{H}_{\mathrm{k}^{\prime}}^{\mathrm{mzf}}=\left[\begin{array}{cc}
\mathrm{H}_{1, \mathrm{k}}^{*} & \mathrm{H}_{2, \mathrm{k}+1} / \mathrm{A}_{\mathrm{k}} \\
\mathrm{H}_{2, \mathrm{k}}^{*} & -\mathrm{H}_{1, \mathrm{k}+1} / \mathrm{A}_{\mathrm{k}}^{*}
\end{array}\right]
$$

where $A_{k}=K_{1, k+1}^{*} K_{2, k+1}$ is the compensation term and $K_{i, m}=H_{i, m} / H_{i, k}$ for $\mathrm{m}=\mathrm{k}+1, \ldots, \mathrm{k}+\mathrm{T}_{\mathrm{f}}-1$ is the difference term between the channel coefficients belonging to the same subcarrier block. The diversity gains then become $\overline{\mathrm{D}}_{\mathrm{k}}=\left|\mathrm{H}_{1, \mathrm{k}}\right|^{2}+\left|\mathrm{H}_{2, \mathrm{k}+1}\right|^{2} / \mathrm{A}_{\mathrm{k}}$ and $\overline{\mathrm{D}}_{\mathrm{k}+1}=$ $\left|\mathrm{H}_{2, \mathrm{k}}\right|^{2}+\left|\mathrm{H}_{1, \mathrm{k}+1}\right|^{2} / \mathrm{A}_{\mathrm{k}}^{*}$.

We can also write $\mathrm{H}_{1, \mathrm{k}+1}=\mathrm{a}_{1, \mathrm{k}} \mathrm{e}^{\mathrm{j} \Delta \mathrm{b}_{1, k}} \mathrm{H}_{1, \mathrm{k}}$ and $\mathrm{H}_{2, \mathrm{k}+1}=\mathrm{a}_{2, \mathrm{k}} \mathrm{e}^{\mathrm{j} \Delta \mathrm{b}_{2, \mathrm{k}} \mathrm{H}_{2, \mathrm{k}}}$ where $\mathrm{a}_{\mathrm{i}, \mathrm{k}}$ and $\Delta \mathrm{b}_{\mathrm{i}, \mathrm{k}}$ are the amplitude and phase differences, respectively, between the channel coefficients of adjacent subcarriers. We then write the compensation term as $A_{k}=a_{1, k} a_{2, k} e^{j\left(\Delta b_{2, k}-\Delta b_{1, k}\right)}$.

To obtain equal and real valued diversity gains for each symbol, by normalising the symbol power, we propose the solution matrix as 


$$
\mathbf{H}_{\mathrm{k}^{\prime}}^{\mathrm{szf}}=\operatorname{diag}\left(1 / \overline{\mathrm{D}}_{\mathrm{k}}, 1 / \overline{\mathrm{D}}_{\mathrm{k}+1}\right) \mathbf{H}_{\mathrm{k}^{\prime}}^{\mathrm{mzf}}
$$

In this case, the proposed matrix $\mathbf{H}_{\mathrm{k}^{\prime}}^{\mathrm{szf}}$ is exactly the inverse of $\mathbf{H}_{\mathrm{k}^{\prime}}$ obtained without performing the $2 \times 2$ matrix inversion.

Using the same principle, we extend the proposed method for orthogonal SFBC-OFDM with $\mathrm{N}_{\mathrm{t}}=3$ by defining the solution matrix as

$$
\mathbf{H}_{\mathrm{k}^{\prime}}^{\mathrm{mzf}}=\left[\begin{array}{cccc}
\mathrm{H}_{1, \mathrm{k}}^{*} & \mathrm{H}_{2, \mathrm{k}+1} / \mathrm{A}_{\mathrm{k}} & -\mathrm{H}_{3, \mathrm{k}+1} / \mathrm{B}_{\mathrm{k}} & 0 \\
\mathrm{H}_{2, \mathrm{k}}^{*} & -\mathrm{H}_{1, \mathrm{k}+1} / \mathrm{A}_{\mathrm{k}}^{*} & 0 & -\mathrm{H}_{3, \mathrm{k}+3} / \mathrm{C}_{\mathrm{k}} \\
\mathrm{H}_{3, \mathrm{k}}^{*} & 0 & \mathrm{H}_{1, \mathrm{k}+2} / \mathrm{B}_{\mathrm{k}}^{*} & \mathrm{H}_{2, \mathrm{k}+3} / \mathrm{C}_{\mathrm{k}}^{*}
\end{array}\right]
$$

where the compensation terms are $A_{k}=K_{1, k+1}^{*} K_{2, k+1}, B_{k}=K_{1, k+2}^{*}$ $\mathrm{K}_{3, \mathrm{k}+2}$ and $\mathrm{C}_{\mathrm{k}}=\mathrm{K}_{2, \mathrm{k}+3}^{*} \mathrm{~K}_{3, \mathrm{k}+3}$. Then, the achievable diversity gains become $\overline{\mathrm{D}}_{\mathrm{k}}=\left|\mathrm{H}_{1, \mathrm{k}}\right|^{2}+\left|\mathrm{H}_{2, \mathrm{k}+1}\right|^{2} / \mathrm{A}_{\mathrm{k}}+\left|\mathrm{H}_{3, \mathrm{k}+2}\right|^{2} / \mathrm{B}_{\mathrm{k}}, \overline{\mathrm{D}}_{\mathrm{k}+1}=\left|\mathrm{H}_{2, \mathrm{k}}\right|^{2}+$ $\left|\mathrm{H}_{1, \mathrm{k}+1}\right|^{2} / \mathrm{A}_{\mathrm{k}}^{*}+\left|\mathrm{H}_{3, \mathrm{k}+3}\right|^{2} / \mathrm{C}_{\mathrm{k}}$ and $\overline{\mathrm{D}}_{\mathrm{k}+2}=\left|\mathrm{H}_{3, \mathrm{k}}\right|^{2}+\left|\mathrm{H}_{1, \mathrm{k}+2}\right|^{2} / \mathrm{B}_{\mathrm{k}}^{*}+$ $\left|\mathrm{H}_{2, \mathrm{k}+3}\right|^{2} / \mathrm{C}_{\mathrm{k}}^{*}$.

Similar to (6), we propose the solution matrix as

$$
\mathrm{H}_{\mathrm{k}^{\prime}}^{\mathrm{szf}}=\operatorname{diag}\left(1 / \overline{\mathrm{D}}_{\mathrm{k}}, 1 / \overline{\mathrm{D}}_{\mathrm{k}+1}, 1 / \overline{\mathrm{D}}_{\mathrm{k}+2}\right) \mathbf{H}_{\mathrm{k}^{\prime}}^{\mathrm{mzf}}
$$

The proposed receivers given in (6) and (8) eliminate the interference terms coming from neighbouring subcarriers while providing diversity gains. The proposed method gives the ZF solution since it satisfies the equality $\mathbf{H}_{\mathrm{k}^{\prime}}^{\mathrm{szf}} \mathbf{H}_{\mathrm{k}^{\prime}}=\mathrm{I}_{\mathrm{Q}}$. Note that this method avoids the inversion of the channel transfer matrix. Hence, we reduce the complexity of the classical ZF receiver from 618 to 342 flops for each subcarrier block for orthogonal SFBC-OFDM with three transmit and one receive antennas. However, since we do not perform the exact pseudo-inversion, the Frobenius norm [6] of the proposed matrix is not minimum. Consequently, there will be a slight performance degradation compared to the classical ZF receiver.

Simulation results and conclusion: We give the simulation results of SFBC-OFDM for QPSIC using the classical and the proposed ZF receivers, the HF receiver, the maximum proposed likelihood (ML).

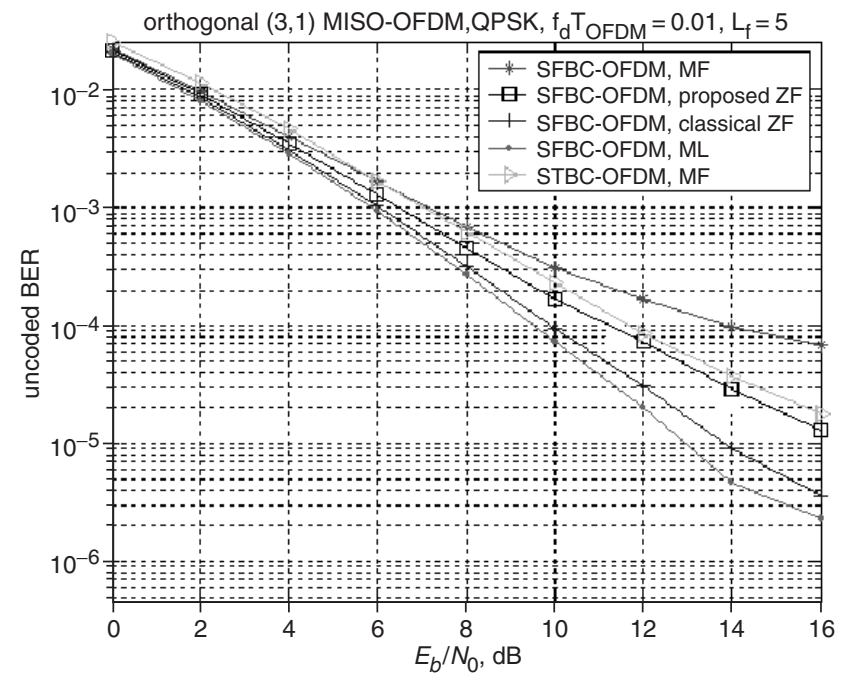

Fig. 1 BER performance of MISO-OFDM in broadband channel with $L_{f}=5$
The symbol duration of the OFDM symbol including GI is set to $\mathrm{T}_{\text {OFDM }}=(\mathrm{K}+\mathrm{K} / 4) \mathrm{T}_{\mathrm{s}}$ where $\mathrm{K}=1024$ and $\mathrm{T}_{\mathrm{s}}=7.4 \mathrm{~ns}$. The $\mathrm{f}_{\mathrm{d}} \mathrm{T}_{\text {OFDM }}$ is chosen as 0.01 . One OFDM symbol consists of 768 symbols. Wireless channels from each transmit to receive antenna are modelled as independent Rayleigh fading using Jakes model. In the power-delay profile (PDP), the time and power differences between the paths are set to $8 \mathrm{~T}_{\mathrm{s}}$ and $0.5 \mathrm{~dB}$, respectively. (The power of the first path is $0 \mathrm{~dB}$.) The frequency correlation coefficients between the subcarriers are calculated as $\rho_{1}=0.997, \rho_{2}=0.991$ and $\rho_{3}=0.97$ where $\rho_{\ell}=$ $\sum_{\mathrm{r}=1}^{\mathrm{L}_{\mathrm{f}}} \sigma_{\mathrm{r}}^{2} \exp (-\mathrm{j} 2 \pi \ell \mathrm{r} / \mathrm{K})$. Since the frequency correlation coefficients are not equal to 1 there are differences between the adjacent subcarriers.

As shown in Fig. 1, the proposed ZF receiver presents the error floor compared to the MF receiver. It has half computational complexity for each subcarrier block while the performance difference is only $1.6 \mathrm{~dB}$ at $10^{-4}$ compared to the classical ZF receiver. Moreover, it provides a $3.2 \mathrm{~dB}$ improvement compared to the MF receiver at $10^{-4}$ while only doubling the complexity. Furthermore, it gives slightly better performance than the STBC-OFDM system while decreasing the delay time in decoding.

While it is generally assumed that SFBC-OFDM using orthogonal designs is a technique limited to the channels where the delay spread is small compared to the symbol duration, we have shown that using the proposed low complexity ZF receiver it is possible to extend the application range of SFBC-OFDM to the broadband wireless channels.

(C) The Institution of Engineering and Technology 2006 30 December 2005

Electronics Letters online no: 20064359

doi: 10.1049/el:20064359

B. Özbek (Electrical and Electronics Engineering Department, Izmir Institute of Technology, Urla, 35430 Izmir, Turkey)

E-mail: bernaozbek@iyte.edu.tr

D. Le Ruyet (Electronics and Communications Laboratory, CNAM, 292 rue Saint Martin, 75141 Paris, France)

\section{References}

1 Lee, K.F., and Williams, D.B.: 'A space-time coded transmitter diversity technique for frequency selective fading channels'. Proc. of Sensor Array and Multichannal Signal Processing Workshop, 2000, pp. 149-152

2 Bolcskei, H., and Paulraj, A.J.: 'Space-frequency coded broadband OFDM systems'. Proc. of IEEE Wireless Communication and Networking Conf., 2000, Vol. 1, pp. 1-6

3 Bauch, G.: 'Space-time-frequency transmit diversity in broadband wireless OFDM systems'. Proc. 8th Int. OFDM Workshop, 2003

4 Alamouti, S.M.: 'A simple transmitter diversity scheme for wireless communications', IEEE J. Sel. Areas Commun., 1998, 16, pp. 1451-58

5 Hochwald, B.M., Marzetta, T.L., and Papadias, C.B.: 'A transmitter diversity scheme for wideband CDMA systems based on space-time spreading', IEEE J. Sel. Areas Commun., 2002, 19, pp. 48-60

6 Golub, G.H., and Van Loan, C.F.: 'Matrix computations' (The Johns Hopkins University Press, 1996) 